\title{
Molar distalisation by pendulum appliance
}

\author{
Santosh Kumar Verma, ${ }^{1}$ Khushboo Rastogi, ${ }^{2}$ Rajarshi Bhushan, ${ }^{1}$ Mahesh Sagar ${ }^{1}$
}

${ }^{1}$ Department of Orthodontics \& Dentofacial Orthopedics, Kothiwal Dental College

$\&$ Research Centre,

Moradabad, Uttar Pradesh, India

${ }^{2}$ Department of Periodontics and Implantology, Kothiwal Dental College \& Research Centre, Moradabad, Uttar Pradesh, India

\section{Correspondence to} Dr khushboo Rastogi, diya2001_rastogi@yahoo.co.in

\section{DESCRIPTION}

The concept of 'distal driving' of maxillary posterior teeth has a long orthodontic history. ${ }^{1}$ Class II malocclusions, which are the most numerous among orthodontic cases, can be resolved by several procedures. ${ }^{1}$ One involves the distal movement of the maxillary molars to establish class I molar relationships. The premolars and canines are then sequentially moved posteriorly to class I positions, and finally the incisors are aligned and/or retracted. ${ }^{2}$ This version of the appliance is called as 'Pend- $X$ '. The pendulum springs are so efficient in expanding and rotating the upper first molars that use the Pend-X for 3 or 4 months at the beginning of treatment whenever any expansion or change in anterior arch form is indicated. ${ }^{3}$ A 13-year-old female patient reported to the department with Angle's class II division 1 molar relationship, lip strain, convex profile with skeletal class I bases, horizontal growth pattern and incompetent lips because of proclination and increased overjet (figures 1-8). The visual treatment objective was not positive and since the skeletal bases were class I we planned for distalisation. Pendulum appliance was used to distalise the upper molars and class I molar relationship was achieved in 6 months and

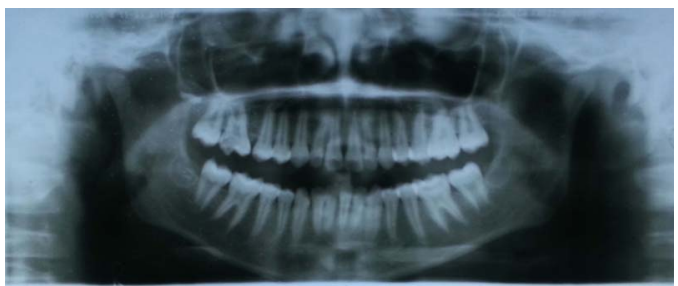

Figure 1 Pretreatment orthopantomograph.

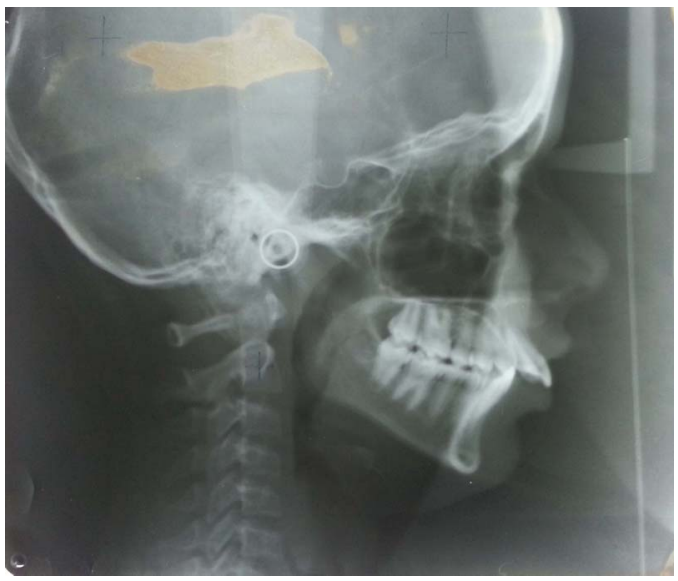

Figure 2 Pretreatment lateral cephalogram.

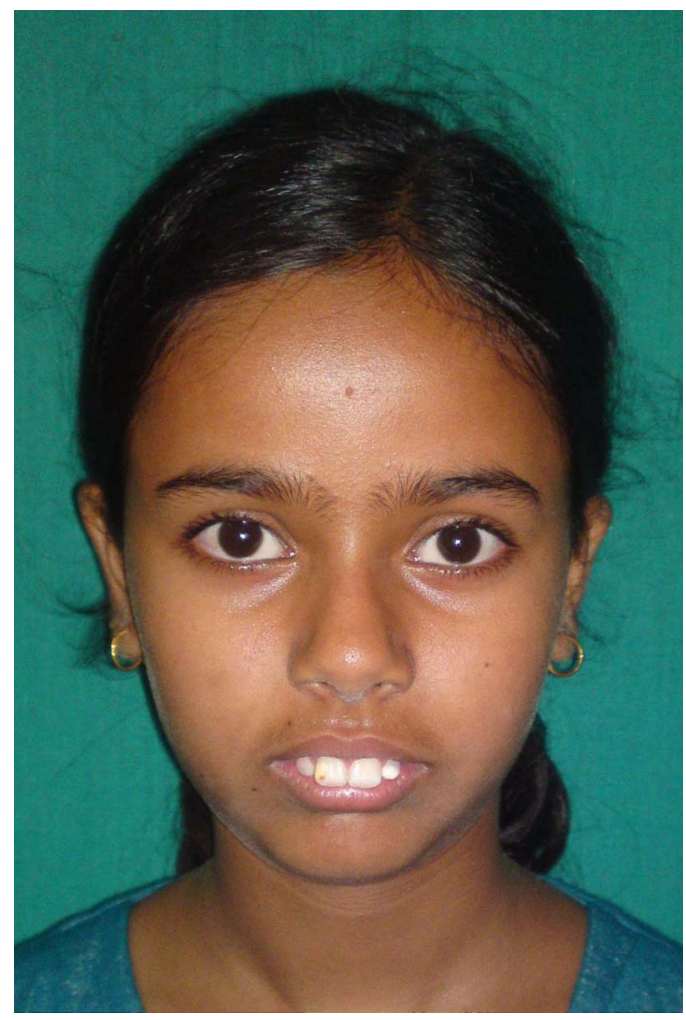

Figure 3 Pretreatment extraoral frontal view.

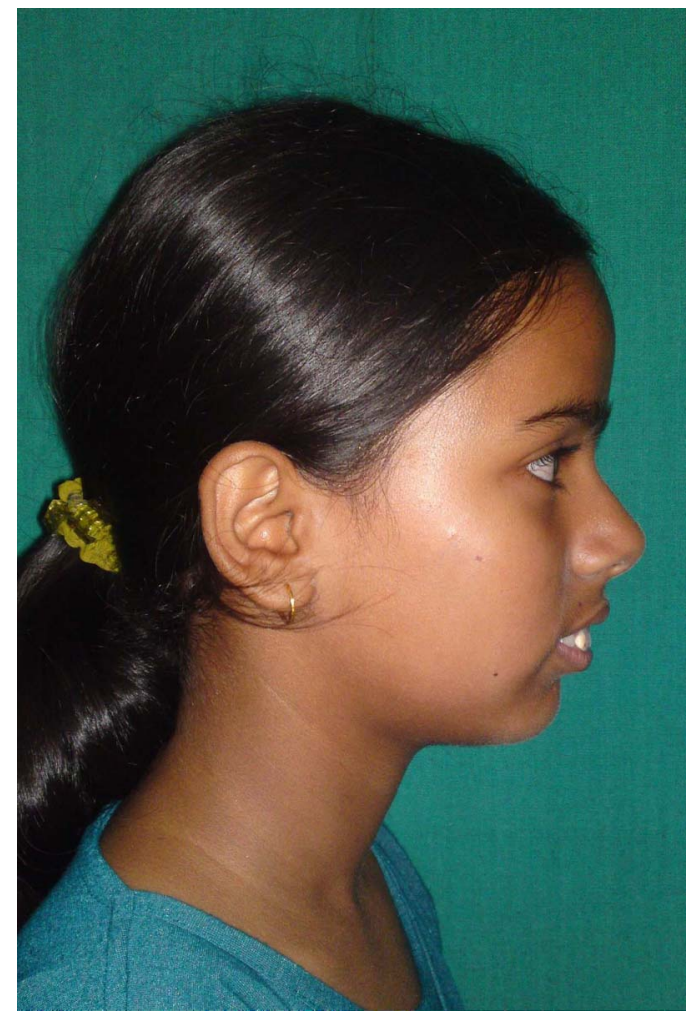

Figure 4 Pretreatment extraoral lateral view. 


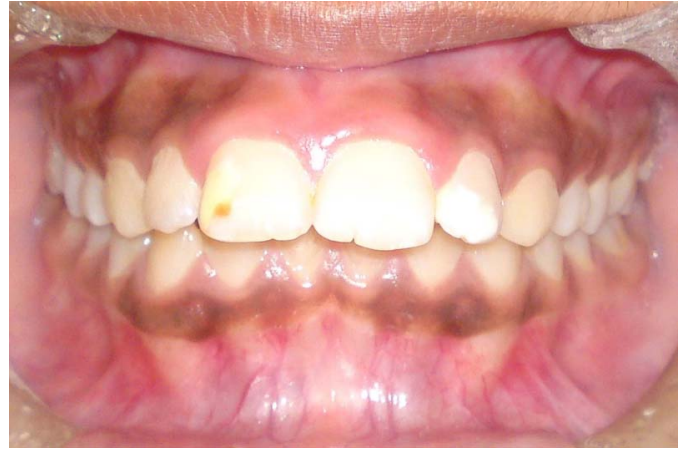

Figure 5 Pretreatment intraoral frontal view.

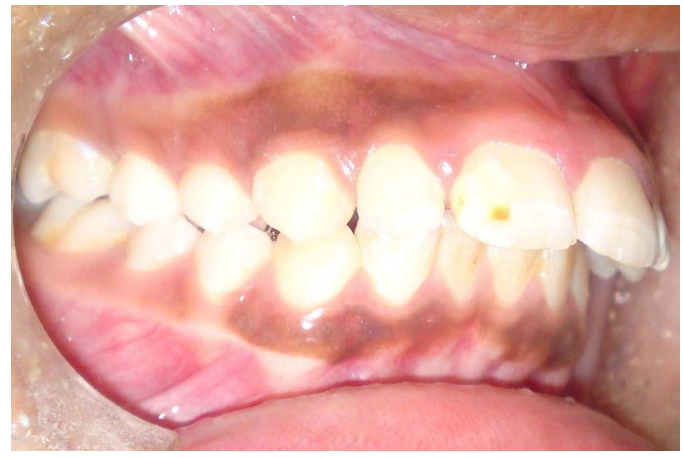

Figure 6 Pretreatment right side occlusal view.

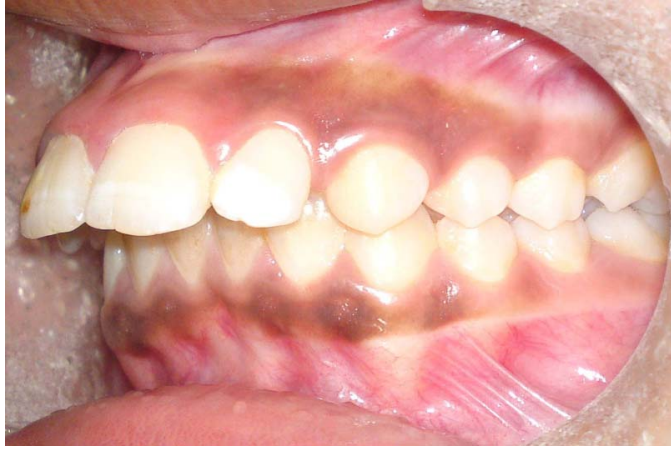

Figure 7 Pretreatment left side occlusal view showing Angle's class II molar relationship.

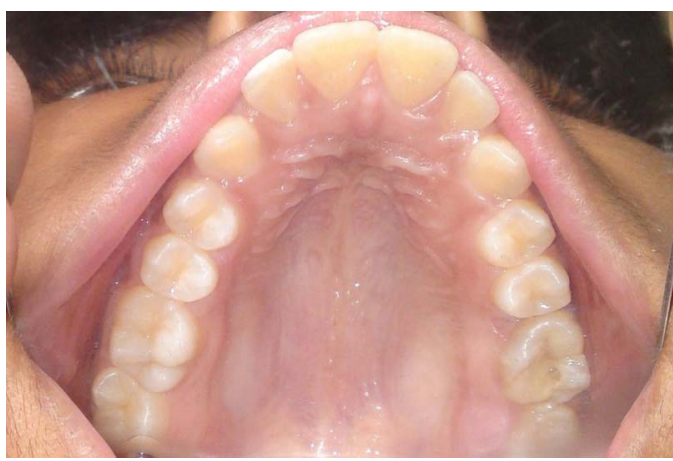

Figure 8 Preoperative view of maxillary arch.

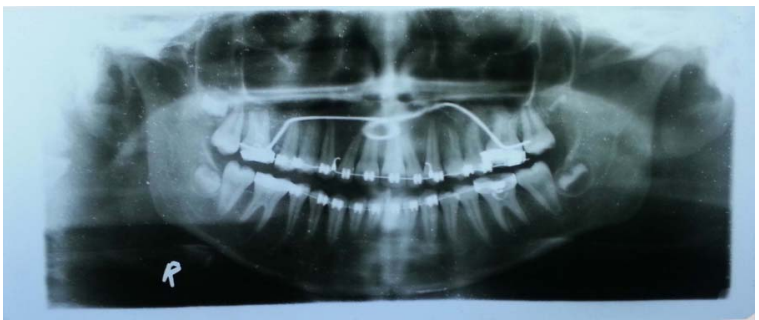

Figure 9 Orthopantomograph after 6 months of molar distalisation.

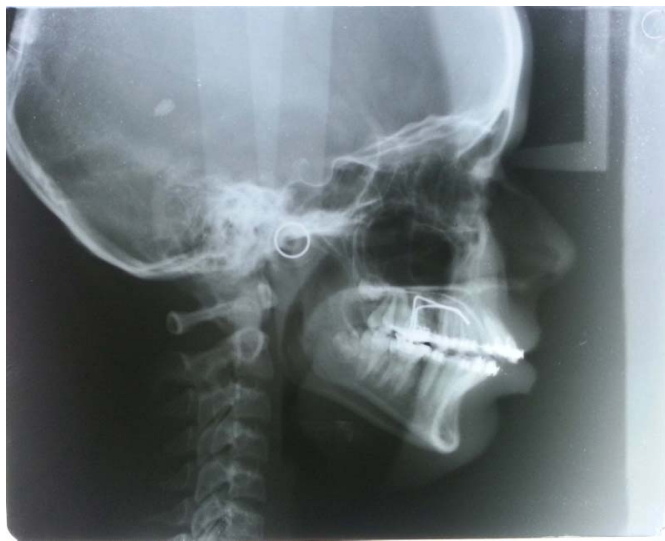

Figure 10 Lateral cephalogram after 6 months of molar distalisation with pendulum appliance.

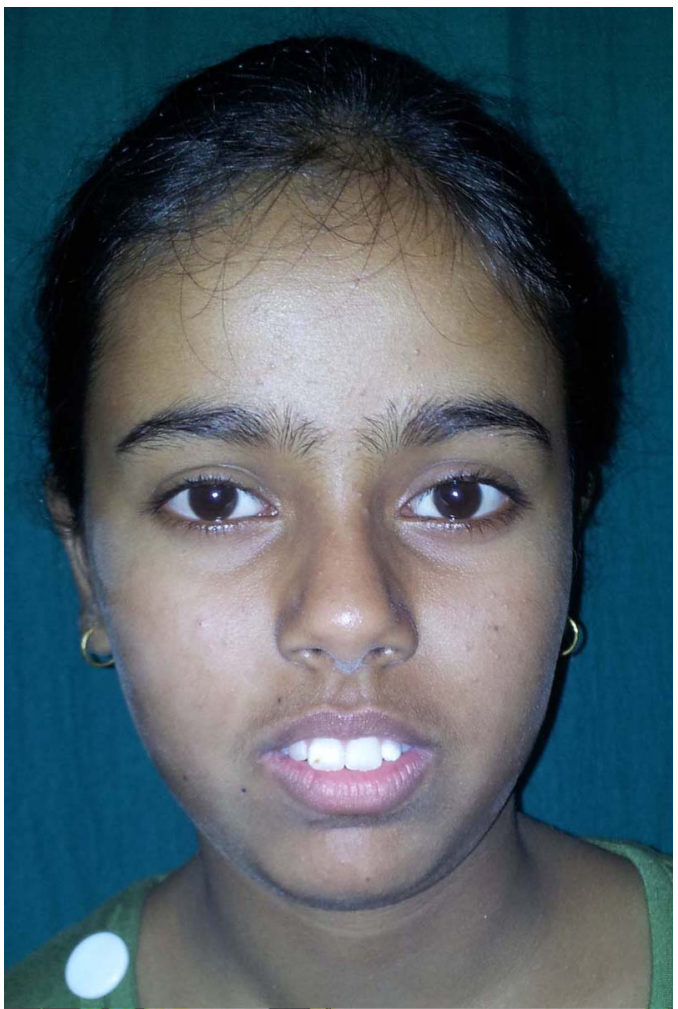

Figure 11 Extraoral frontal view after 6 months of treatment with pendulum appliance. 


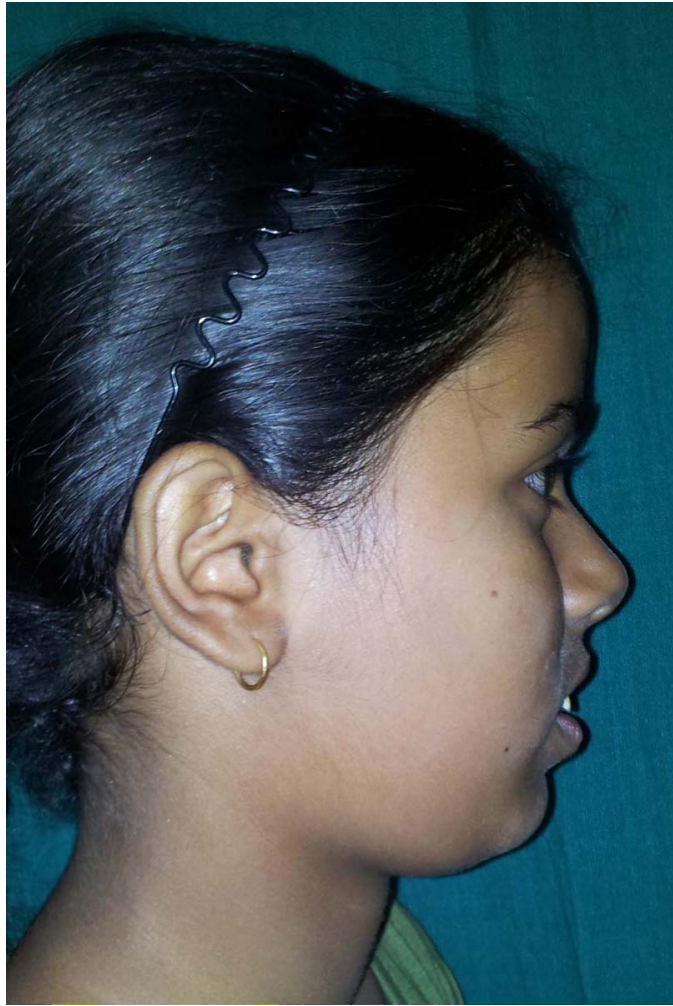

Figure 12 Extraoral lateral view after 6 months of treatment with pendulum appliance.

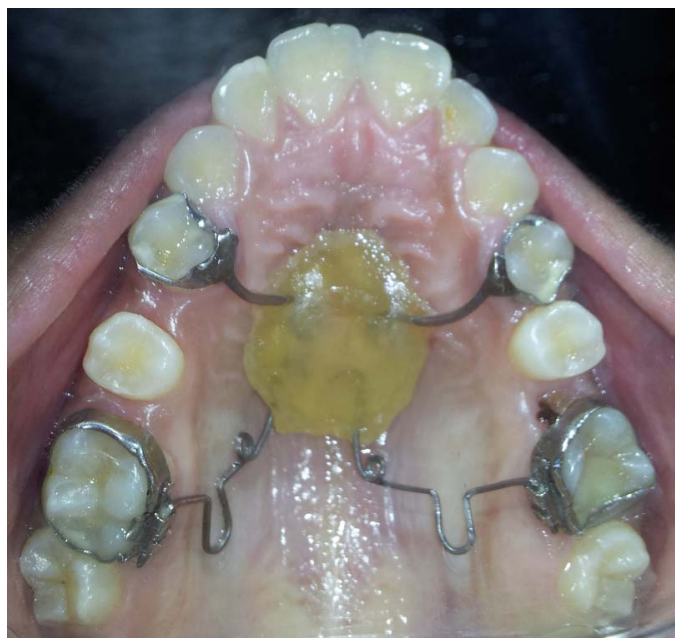

Figure 13 Maxillary arch with pendulum appliance and the space created after molar distalisation in 6 months.

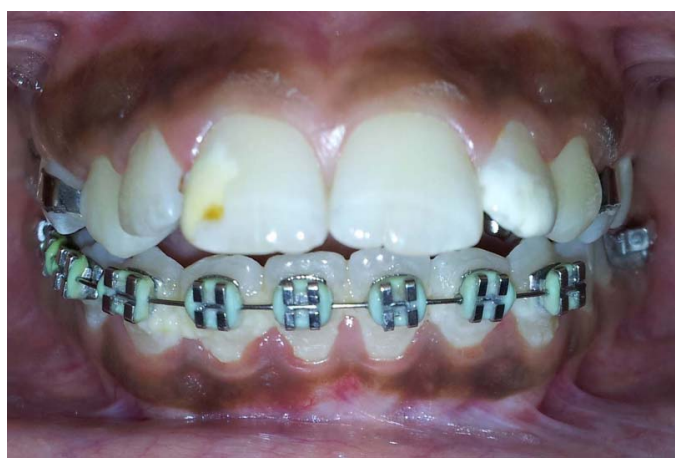

Figure 14 Frontal view after 6 months.

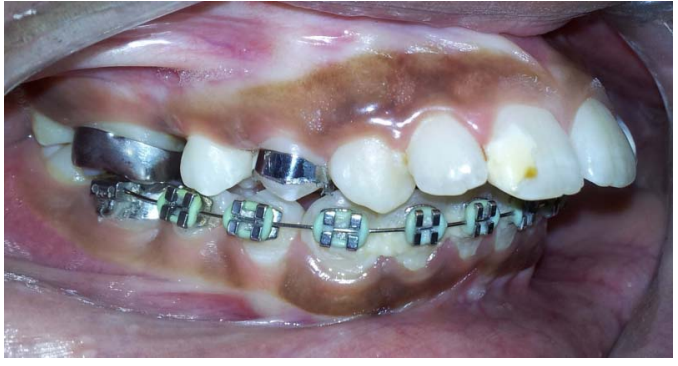

Figure 15 Left side occlusal view showing Angle's class I molar relationship in just 6 months after molar distalisation with pendulum appliance.

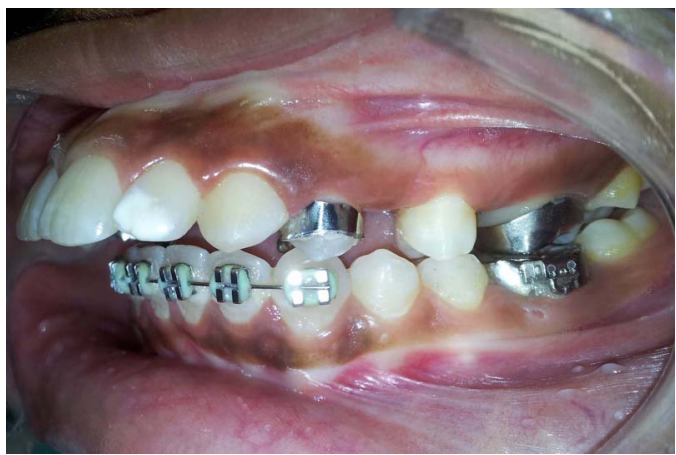

Figure 16 Right side occlusal view showing Angle's class I molar relationship in just 6 months after molar distalisation with pendulum appliance.

$10 \mathrm{~mm}$ of space was created. The space gained was used in the correction of maxillary anterior proclination and hence correcting the lip strain and improving the lip incompetency. The figures depicts correction of Angle's class II molar relationship to class I and gaining $10 \mathrm{~mm}$ of space by distalising the molars with pendulum appliance (figures 9-16).

\section{Learning points}

- Molar distalisation is a very good option in non-complaint class II patients.

- Pendulum is a good choice of appliance for molar distalisation.

With pendulum appliance there is good rotational control.

\section{Competing interests None.}

Patient consent Obtained.

Provenance and peer review Not commissioned; externally peer reviewed.

\section{REFERENCES}

1 Proffit WR. Contemporary orthodontics: 3rd edn. Missouri: Mosby Publications, 2007:260-72, 317-321, 340-41, 494-502.

2 Gianelly AA, Vaitas AS, Thomas W, et al. Distalization of molars with repelling magnets. J Clin Orthod 1988:22:40-4.

3 Hilgers JJ. The pendulum appliance for class II non-compliance therapy. I Clin Orthod 1992:26:706-14. 


\section{Images in...}

Copyright 2013 BMJ Publishing Group. All rights reserved. For permission to reuse any of this content visit http://group.bmj.com/group/rights-licensing/permissions.

BMJ Case Report Fellows may re-use this article for personal use and teaching without any further permission.

Become a Fellow of BMJ Case Reports today and you can:

- Submit as many cases as you like

- Enjoy fast sympathetic peer review and rapid publication of accepted articles

- Access all the published articles

- Re-use any of the published material for personal use and teaching without further permission

For information on Institutional Fellowships contact consortiasales@bmjgroup.com

Visit casereports.bmj.com for more articles like this and to become a Fellow 